\title{
Characterization of Laser-Generated Microparticles by Means of a Dust Monitor and SEM Imaging
}

\author{
Roland Wurster, ${ }^{1}$ Simone Pentzien, ${ }^{2}$ Andrea Conradi,, ${ }^{2}$ and Jörg Krüger ${ }^{2}$ \\ ${ }^{1}$ Institute for Physics and Meteorology, Hohenheim University, Garbenstraße 30, 70599 Stuttgart, Germany \\ ${ }^{2}$ Division VI.4 Surface Technologies, Federal Institute for Materials Research and Testing (BAM), \\ Unter den Eichen 87, 12205 Berlin, Germany
}

Received 13 September 2006; Revised 9 November 2006; Accepted 16 November 2006

Recommended by Costas Fotakis

\begin{abstract}
Nanosecond laser (1064 nm wavelength) cleaning of artificially soiled paper as a model sample simulating a real-world artwork was performed. During the cleaning process, the ejection of particles was monitored in situ by means of a dust monitor ( 8 size classes, ranging from $0.3 \mu \mathrm{m}$ to $>2 \mu \mathrm{m}$ ) and ex situ using a mini-cascade impactor (MKI, 5 stages). The cleaning result was analyzed by scanning electron microscopy (SEM) considering possible laser-induced damages to the substrate. Size distributions of emitted particles were measured depending on the processing parameters: laser fluence, $F$, and pulse number per spot, $N$. High numbers of large $(>2 \mu \mathrm{m})$ particles were collected by the mini-cascade impactor indicating a gas dynamical liftoff process. Obviously, these particles were not affected by the laser-matter interaction. The different methods (SEM, MKI, and dust monitor) are compared with respect to their usefulness for a proper interpretation of the cleaning results.
\end{abstract}

Copyright (c) 2006 Roland Wurster et al. This is an open access article distributed under the Creative Commons Attribution License, which permits unrestricted use, distribution, and reproduction in any medium, provided the original work is properly cited.

\section{INTRODUCTION}

Laser cleaning of soiled paper is a challenging task due to the fact that a contamination (e.g., a layer, dispersed foreign material or even particulates) has to be removed and a fragile organic material has to be preserved. Laser radiation offers the potential of a spatial and temporal concentration of energy. In an ideal case, the laser energy can be deposited in a sharply defined volume of the soil to remove it and leave the paper intact. In reality, laser cleaning of paper is a complex process depending on the (optical, thermal, chemical, and mechanical) properties of the pollutant and of the matrix and also on the laser parameters like wavelength, pulse duration, spatial intensity distribution, and repetition rate. In recent years, a few papers were published concerning the topic [1-8]. To avoid an undesirable destruction of the paper, a working range for the laser has to be found. The laser parameters have to be chosen that the damage threshold of the matrix material is not reached. Generally, the term "damage" includes immediate as well as long-term effects which might cause an irreversible change of the paper material (e.g., thermal destabilization of the substrate $[2,8]$, color changes $[4,5]$, and any influence on the ageing behavior [8]).
An in situ monitoring process of the laser cleaning procedure is desirable. Laser-induced breakdown spectroscopy of the plasma plume (LIBS [9]) and acoustic techniques [8] were established. The ejection of particles forms a major channel for the removal of unwanted surface layers. The micro-analytical characterization of particles ejected from the contamination film can be a source of complementary information [10]. However, this paper aims at a multimethod approach by in situ (dust monitor) and ex situ investigations (SEM and mini-cascade impactor) of $1064 \mathrm{~nm}$ nanosecond laser processing of sensitive samples to determine a laser working range $(F, N)$ and to understand the mechanism of the cleaning process.

\section{EXPERIMENTAL}

Charcoal was mechanically rubbed and distributed with a brush on a Whatman filter paper no. 1506. The pulverized soiling was sucked in with a hoover for 2 minutes to achieve a stable contact between pollution and paper. The model samples should simulate a real-world artwork. Homogeneity of the soiling was controlled down to a lateral scale of $<0.5 \mathrm{~mm}$. Differences of lightness measurements of $\pm 10 \%$ 


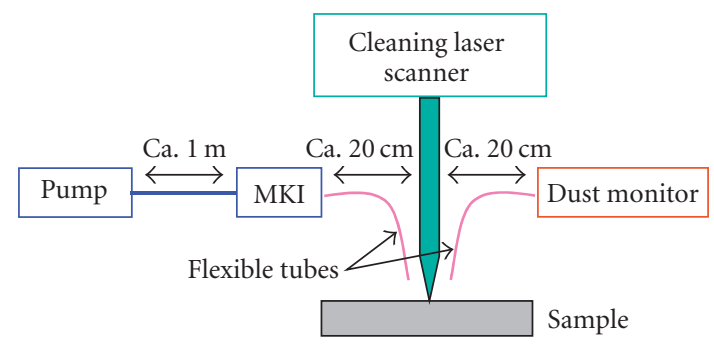

FIGURE 1: Scheme of the experimental setup.

were detected employing a multispectral imaging system (MUSIS 2007, Model D-HFA-12). Energy dispersive X-ray spectra of the model system clearly showed major $(\mathrm{C}, \mathrm{O})$ and minor $(\mathrm{K}, \mathrm{Ca}, \mathrm{Cu}, \mathrm{Zn})$ elemental components of the powder.

The experimental setup is depicted in Figure 1 showing the laser cleaning system combined with two particle collection devices (dust monitor and MKI). A computercontrolled cleaning station [11] was applied for the laser treatment. The Nd: YAG-laser was operated in its fundamental mode at $1064 \mathrm{~nm}$ wavelength at a pulse duration of $8 \mathrm{~ns}$ and a repetition rate of $500 \mathrm{~Hz}$. The laser fluence $F$ was varied between 0.45 and $12.8 \mathrm{~J} / \mathrm{cm}^{-2}$. Depending on the number of laser pulses per spot, a $3 \mathrm{~mm}$ square was scanned in $9 \mathrm{sec}-$ onds (for $N=1$ ) or 7 minutes $(N=36$ ), respectively. For safety reasons, the whole laser-processing compartment fulfils Laser Class I conditions.

During the cleaning procedure, a commercial dust monitor (Portable Dust Monitor Mod. 1.108, GRIMM-Aerosol Technik) was used for the measurement of particle size distributions in airborne state. The aerosol inlet of the dust monitor is positioned next to the laser impact area $(1 \mathrm{~mm}$ distance). Particle size distributions (eight size classes) were recorded at a time resolution of one second. The single particle detection bases on light scattering (using a laser diode) with a minimal detectable particle size of $0.3 \mu \mathrm{m}$. Aerosol flow control was adjusted and stabilized to $1.2 \mathrm{l} / \mathrm{min}$.

Additionally, particles released from the treated area were collected actively with an aerosol flow of $0.71 / \mathrm{min}$ by means of a five stage mini-cascade impactor (MKI) both on ultrathin substrate films (pioloform) covering standard made copper grids and $\mathrm{Al}$ foils for off-line microscopic inspection. Scanning electron microscopy (high resolution SEM ABT DS 150F, Topcon, Tokyo) was applied to collected particles (MKI) and irradiated sample areas as well.

\section{RESULTS AND DISCUSSION}

Figure 2 displays the result of the preparation of the model samples. The SEM pictures show the original surface morphology of a Whatman filter paper (Figure 2(a)) and the appearance after the mechanical soiling of the paper (Figure 2(b)). It can be clearly seen that the structure of the paper was not modified due to the mechanical conditioning.

The results of single-pulse $(N=1)$ laser processing tests utilizing different laser fluences (energy densities) are depicted in Figure 3. For these illumination conditions, the

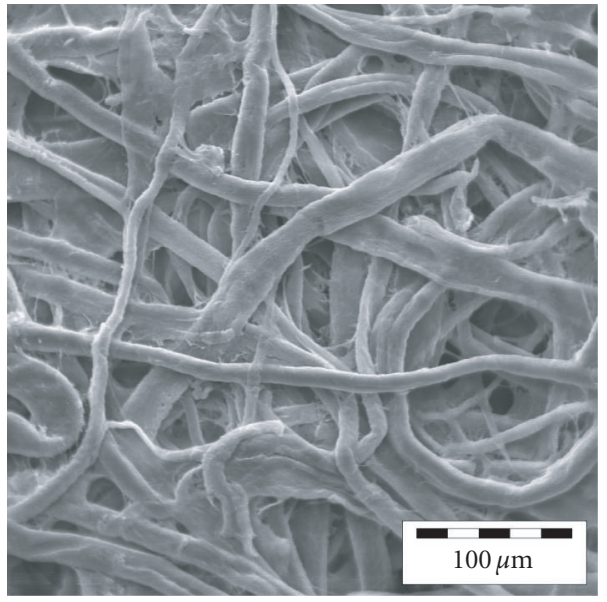

(a)

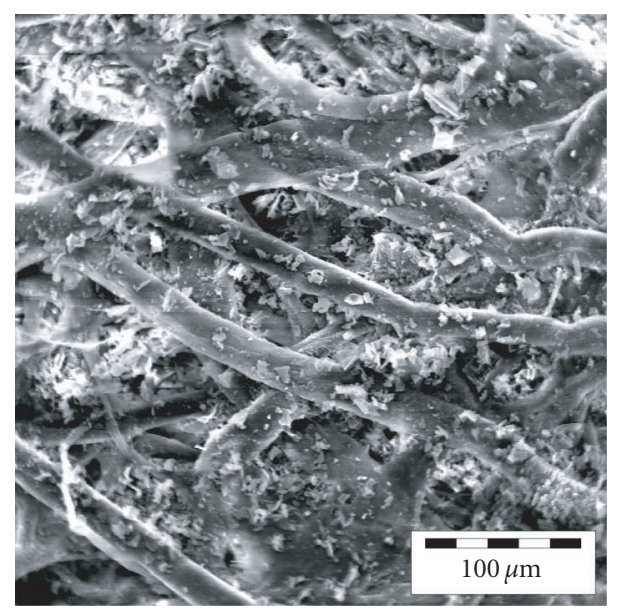

(b)

FIGURE 2: Scanning electron microscope (SEM) pictures of Whatman filter no. 1506: (a) as received, (b) mechanically soiled with charcoal dust.

cleaning effect increases with rising laser fluence up to the maximum value of $12.8 \mathrm{~J} / \mathrm{cm}^{-2}$ which was the highest achievable energy density for the focusing conditions described here.

After laser illumination with energy densities up to about $2 \mathrm{~J} / \mathrm{cm}^{-2}$ (areas "A"-"D", Figure 3), a discoloration (yellowing) of the treated samples was not observed with the multi spectral imaging system MUSIS 2007. A closer inspection of a part of area "E" (Figure 3) is illustrated in Figure 4. Obviously, a satisfying cleaning effect could be reached (compare Figure 2(b)). The paper structure remained unchanged (compare the original paper surface without any soiling in Figure 2(a)) and no evidence of laser-induced damage can be observed. It should be pointed out that this result was obtained for the application of one single laser pulse per spot and cannot be transferred to multipulse conditions.

During the removal of the soil, ejected particles were deposited onto five stages of a mini-cascade impactor (MKI [12]). The impact of particles occurred according to the 


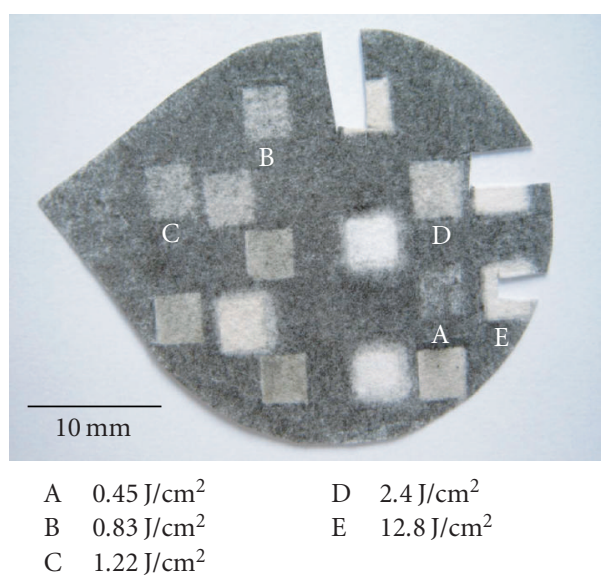

FIGURE 3: Results of different cleaning procedures with varying laser fluence and $N=1$.

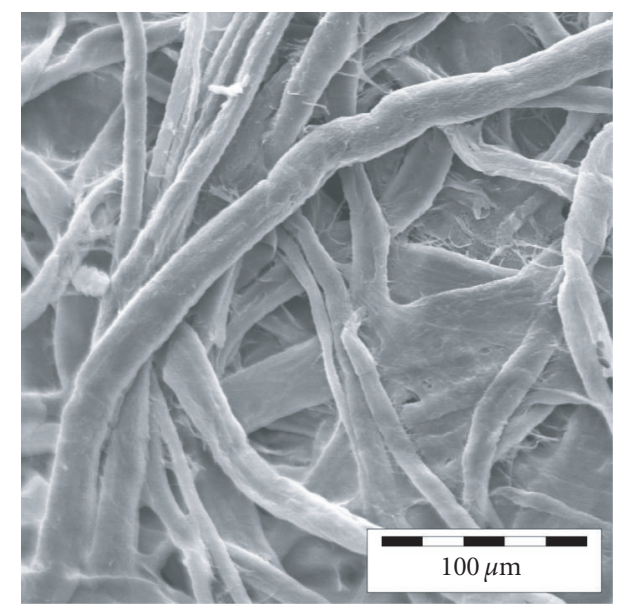

FIGURE 4: SEM picture of a cleaning result after a laser treatment with $N=1$ and $F=12.8 \mathrm{~J} / \mathrm{cm}^{-2}$.

aerodynamic size decreasing from stage 1 to stage 5. SEM pictures of particles deposited on stages 2 and 5 of the MKI are depicted in Figure 5.

The coarse particles (Figure 5(a)) do not show any modification of shape and morphology induced by the laser illumination while the fine particles (Figure 5(b)) tend to have a convex and well-rounded shape. The latter is attributed to a laser-induced melting process. The investigation of aerodynamically separated particle size fractions leads to the conclusion that especially an efficient mechanical liftoff behavior contributes to the laser cleaning process.

During the laser processing of the model samples, size distributions of ejected particles were recorded. Particle concentrations right next to the laser-treated surface exceeded the background aerosol concentration of the laboratory air by 2 to 4 orders of magnitude. Figure 6 displays the dependence of the particle concentration on the size class employ-

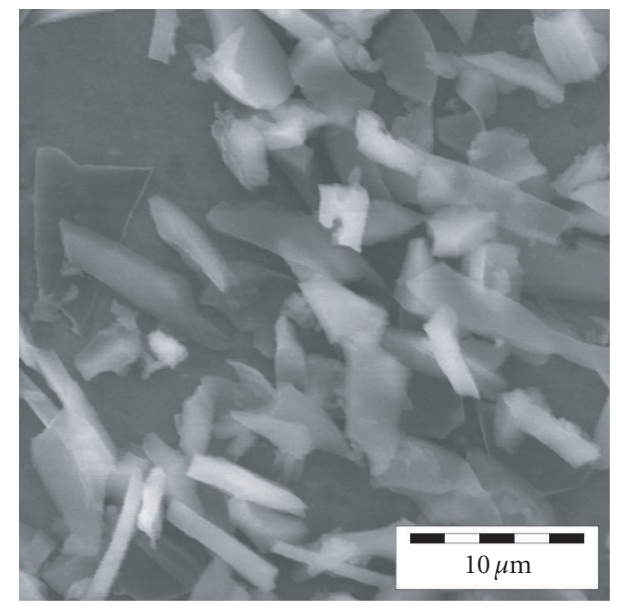

(a)

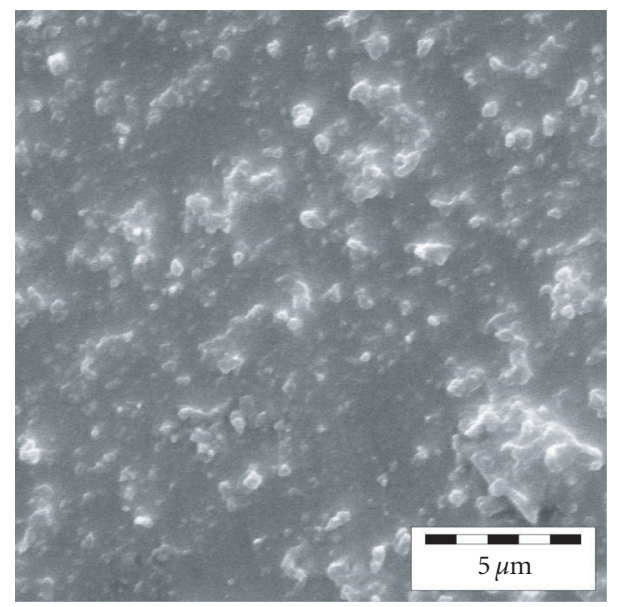

(b)

FIGURE 5: SEM pictures of particles deposited on different stages ((a) stage 2, (b) stage 5) of the mini-cascade impactor (MKI) during laser cleaning with $N=1$ and $F=12.8 \mathrm{~J} / \mathrm{cm}^{-2}$.

ing five different laser fluences. For comparison, laser pulses with the maximum fluence of $12.8 \mathrm{~J} / \mathrm{cm}^{-2}$ were impinged on the filter paper without soil. The difference of the signal (particles/litre) for the samples with and without contamination was evident. For all fluences applied, a peak-valley structure of the signal versus size class curve was found. This behavior may reflect different particle production and emission paths but is not yet understood. An artefact of the measuring system can be ruled out. Contrary to Figure 6 for a realworld soiled paper, a deviating curve was found (Figure 7). For the model sample (Figure 6), the number concentration of particles for all size classes was not a monotone function of the laser fluence. Only for the two lowest fluences, the particle number concentrations did increase with increasing energy density in all 8 size categories. For the highest fluence of $12.8 \mathrm{~J} / \mathrm{cm}^{-2}$ and the application to the soiled paper, a significant enhancement of the recorded number concen- 


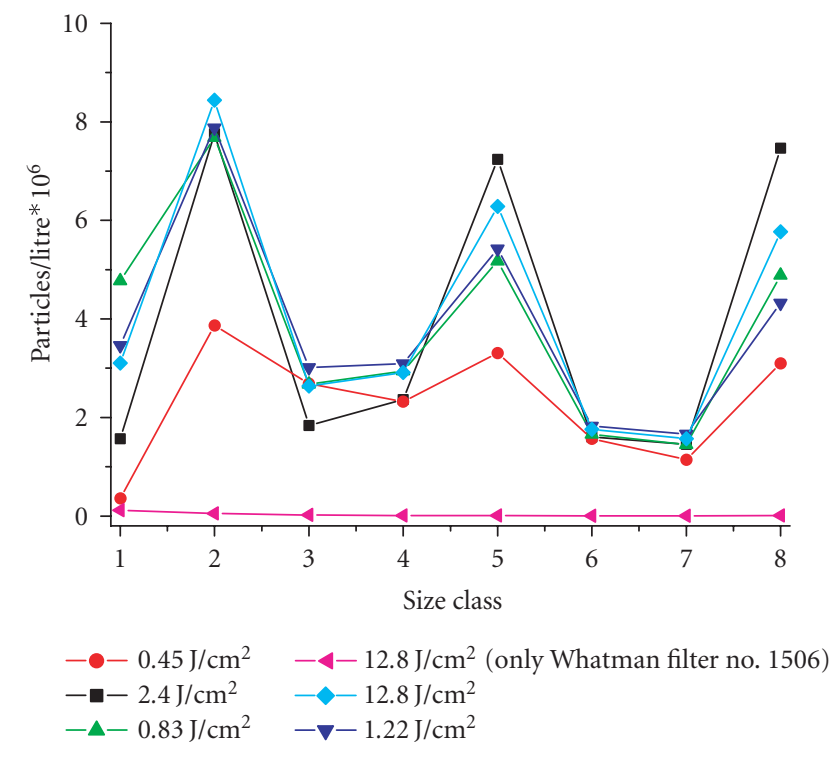

FIGURE 6: Size distribution of laser-ablated particles for different fluences applied and single-pulse illumination conditions. Each data point represents the average over an integration time of $5 \mathrm{sec}$ onds. Size class $1=0.3-0.4 \mu \mathrm{m}$, size class $2=0.4-0.5 \mu \mathrm{m}$, size class $3=0.5-0.65 \mu \mathrm{m}$, size class $4=0.65-0.8 \mu \mathrm{m}$, size class $5=$ $0.8-1.0 \mu \mathrm{m}$, size class $6=1.0-1.6 \mu \mathrm{m}$, size class $7=1.6-2.0 \mu \mathrm{m}$, size class $8>2.0 \mu \mathrm{m}$.

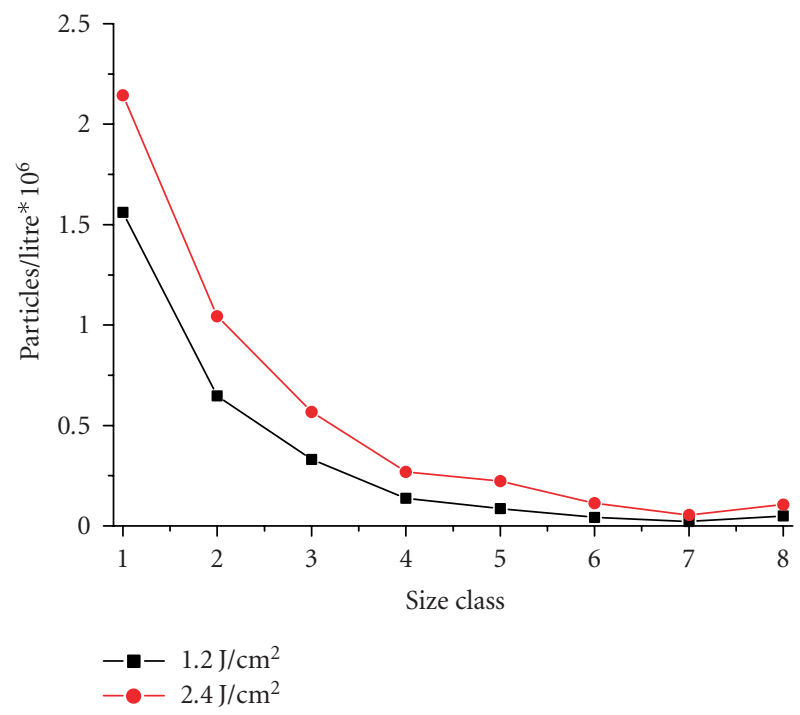

FIgURE 7: Size distribution of laser-ablated particles for two different laser fluences and single-pulse illumination conditions for a real-world sample (drawing board soiled with soot).

trations was not observed. Therefore, most probably the paper stayed intact and the signal can mainly be attributed to the carbon particles (and no additional cellulose particles). This observation corresponds to the SEM picture (Figure 4) that shows the cleaning result after a laser treatment with the same parameters.

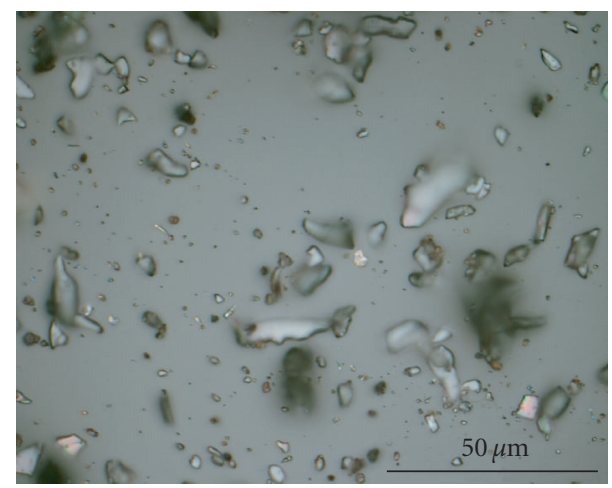

FIGURE 8: Optical microscope picture of a part of the soiling particles.

To get an information about the sizes of the soiling particles before laser illumination, a model sample was beat and the particles were collected on a microscopic slide. An optical microscopic picture was taken (Figure 8), and the number of large $(>2.0 \mu \mathrm{m})$ and small particles $(\sim 0.3 \mu \mathrm{m})$ was counted visually. A ratio of about $1: 1$ was found between these "extreme" size classes.

Comparing this rough estimation of the fine to coarse particle number ratio to the measured size distributions of laser-ablated particles (Figure 6), it may cautiously be stated that no preferential particle removal does occur for these experimental conditions.

\section{CONCLUSIONS}

Nanosecond laser cleaning of artificially soiled paper was carried out. For single-pulse treatment, an improved cleaning effect could be observed for an increasing laser fluence up to an energy density of $12.8 \mathrm{~J} / \mathrm{cm}^{-2}$. SEM revealed that the paper structure remained unchanged. During the cleaning process, laser-generated particle concentrations exceeded the background laboratory air level by 2 to 4 orders of magnitude. The measurements with the dust monitor confirmed the SEM investigations with respect to the damage threshold of the paper. Mini-cascade impactor investigations of aerodynamically separated particle size fractions suggest an efficient mechanical liftoff process contributing to the laser cleaning. A significant preferential ejection of a particular size class could not be observed for the model sample.

\section{REFERENCES}

[1] W. Kautek, S. Pentzien, P. Rudolph, J. Krüger, and E. König, "Laser interaction with coated collagen and cellulose fibre composites: fundamentals of laser cleaning of ancient parchment manuscripts and paper," Applied Surface Science, vol. 127-129, pp. 746-754, 1998.

[2] J. Kolar, M. Strlič, S. Pentzien, and W. Kautek, "Near-UV, visible and IR pulsed laser light interaction with cellulose," Applied Physics A, vol. 71, no. 1, pp. 87-90, 2000.

[3] J. Kolar, M. Strlič, D. Müller-Hess, et al., "Near-UV and visible pulsed laser interaction with paper," Journal of Cultural Heritage, vol. 1, supplement 1, pp. 221-224, 2000. 
[4] M. Strlič, J. Kolar, V.-S. Šelih, and M. Marinček, "Surface modification during Nd:YAG (1064 nm) pulsed laser cleaning of organic fibrous materials," Applied Surface Science, vol. 207, no. 1-4, pp. 236-245, 2003.

[5] P. Rudolph, F. J. Ligterink, J. L. Pedersoli Jr., et al., "Characterization of laser-treated paper," Applied Physics A, vol. 79, no. 2, pp. 181-186, 2004.

[6] P. Rudolph, F. J. Ligterink, J. L. Pedersoli Jr., et al., "Laserinduced alteration of contaminated papers," Applied Physics A, vol. 79, no. 4-6, pp. 941-944, 2004.

[7] A. Kamińska, M. Sawczak, M. Ciepliński, G. Śliwiński, and B. Kosmowski, "Colorimetric study of the post-processing effect due to pulsed laser cleaning of paper," Optica Applicata, vol. 34, no. 1, pp. 121-132, 2004.

[8] M. Strlič, V.-S. Šelih, J. Kolar, et al., "Optimisation and on-line acoustic monitoring of laser cleaning of soiled paper," Applied Physics A, vol. 81, no. 5, pp. 943-951, 2005.

[9] K. Melessanaki, A. Mastrogiannidou, S. Chlouveraki, S. C. Ferrence, P. P. Betancourt, and D. Anglos, "Analysis of archaeological objects with LMNTI, a new transportable LIBS instrument," in Lasers in the Conservation of Artworks, K. Dickmann, C. Fotakis, and J. F. Asmus, Eds., pp. 443-451, Springer, New York, NY, USA, 2005.

[10] R. Wurster, S. Pentzien, and W. Kautek, "Imaging and mass spectrometry of microparticles generated during surface decontamination of an ancient parchment sample by laser radiation," in Lasers in the Conservation of Artworks, LACONA VI Proceedings, Springer, New York, NY, USA, 2006.

[11] W. Kautek and S. Pentzien, "Laser cleaning system for automated paper and parchment cleaning," in Lasers in the Conservation of Artworks, K. Dickmann, C. Fotakis, and J. F. Asmus, Eds., p. 403, Springer, New York, NY, USA, 2005.

[12] P. Wieser and R. Wurster, "Application of laser-microprobe mass analysis to particle collections," in Physical and Chemical Characterization of Individual Airborne Particles, K. R. Spurny, Ed., pp. 251-270, Ellis Horwood, Chichester, UK, 1986. 